\title{
The Polymeric Heterogemeous Matrix for Carbon and Glass Reinforced Plastic
}

\author{
Galina Malysheva ${ }^{1}$, Lianhe Liu ${ }^{2}$, Xiao Ouyang ${ }^{3}$, Oleg Kulakov ${ }^{1}$ \\ ${ }^{1}$ Department of Special Machinery, Bauman Moscow State Technical University, Moscow, Russia \\ ${ }^{2}$ Qingdao Advanced Marine Material Technology Co., Ltd, Qingdao, China \\ ${ }^{3}$ Department of Material Science and Chemical Engineering, Harbin Engineering University, Harbin, China \\ Email: malyin@mail.ru
}

Received August 2013

Copyright (c) 2013 Galina Malysheva et al. This is an open access article distributed under the Creative Commons Attribution License, which permits unrestricted use, distribution, and reproduction in any medium, provided the original work is properly cited.

\begin{abstract}
This article presents the results of deformation-strength properties measurement and microstructural analysis of heterogeneous polymer matrix consisting of thermoset and thermoplastic polymers. Thermosetting material is a diamino-diphenil sulfon-cured epoxy oligomer. Polysulfone was used as thermoplastic material. Two different technological processes were used to obtain heterogeneous polymer matrix: the material was mixed in the block, or layered material was produced in which a layer of thermoplastic material alternated with a layer of epoxy oligomer.
\end{abstract}

Keywords: Heterogeneous Matrix; Polysulfon; Epoxy Olygomer; Interphase Boundary; Microstructure; Polymer Composite Materials

\section{Introduction}

Polymer composite material (PCM) matrix ensures the material solidity and uniform load distribution between the reinforcing elements, resulting in the growth of cracks deceleration, as well as stress transfer and distribution. The most widespread matrix used in production of PCM construction products is epoxy-based binding. The main advantages of epoxy bindings are high adhesive durability, good technological effectiveness, small swelling levels and very good technological properties. This allows creating materials which can be cured at the room temperature (cold-curing binding) and at increased temperatures (hot-curing binding). However, epoxy polymers are rather fragile, generally, their stretch ratio does not exceed $1 \%$, so the search of effective ways of their modification for the deformation properties increase is needed.

The purpose of this work is the development of the epoxy binding with improved deformation properties. To achieve this goal, thermoplastic polymers were used as plasticizers.

\section{Experimental Process}

Traditional epoxy plasticizers, such as dibutylphthalate, active diluents or rubbers, ensure molecular plasticization and allow increasing the characteristics of impact strength and crack resistance, yet their input results in elastic modulus and glass-transition temperature decrease.

One of modern methods of drastic increase of epoxy binding deformation characteristics that does not result in deterioration of their heat resistance and other operating specifications, is use of thermoplasts which relate to type of structural plasticization. Using these polymer mixes as basis makes it possible to create new type of hybrid matrix with high deformation, strength, thermal and physical properties, offering high chemical resistance and good fabricating characteristics.

The most prevailing thermoplasts are polyetherketones, polyesterimides and polysulfones.

In this work the microstructure of the polymer mixes prepared by two different technologies was researched: first, epoxy oligomer and polysulfone mix was prepared, second, the multilayered material consisting of alternating layers of epoxy oligomer and polysulfone was prepared.

In accordance with the first technology, epoxy oligomer and polysulfon mixing were performed using a mechanical mixer at $+180^{\circ} \mathrm{C}$. Afterwards this polymer mixture was cooled, injected with a curing solution and repeatedly mixed by the same mechanical mixer. Curing was held at $+180^{\circ} \mathrm{C}$ during 3 hours. The produced ma- 
terial was used for producing standard test samples. Samples were used for bending ( $\underline{\sigma}_{\text {bend }}$, GOST 9626-90), stretching ( $\varepsilon$, GOST 11262-80) and impact strength (A. GOST 14235-69) testing.

\section{Results and Discussions}

Values for polymer deformation and strength properties in relation to the polysulfon amount injected are given in Table 1.

As seen in Table 1, thermoplast injection to the epoxy matrix increases the bend durability and impact strength more than twice. Also the stretch ratio shows magnitude increase thus indicating fundamental positive influence of thermoplast on deformation properties of system. However, the value of adhesive power slightly decreases depending upon the thermoplastic polymer increase. This phenomenon probably occurs due to the overall viscosity growth, resulting in the lbinding layer thickness being slightly higher than the optimum. Yet such an insignificant reduction of adhesive power is not fundamental and will not lead to the deterioration of fabricating characteristics of PCM based on this polymer matrix.

In accordance with the second technology, epoxy olihomer and polysulfone joint mixing was not performed. Multilayered material with epoxy oligomer and polysulfone layers alternated among themselves was made.

This multilayered binding production technology includes several stages. Compression-molded polysulfone thin films were produced. The film thickness reached 100 - 140 microns. The epoxy oligomer preliminarily mixed with a curing compound was manually coated on the polysulfone film surface. Afterwards the next polysulfone layer was coated. Three types of multilayered samples were produced:

- 3 layers (2 polysulfone layers, 1 epoxy olygomer layer);

- 5 layers (3 polysulfone layers, 2 epoxy olygomer layers);

- 7 layers (4 polysulfone layers, 3 epoxy olygomer layers) (see Table 2).

Table 1. Influence of the thermoplastic material content on the properties of heterogemeous matrix (epoxy resin + polysulfone).

\begin{tabular}{|c|c|c|c|c|c|c|}
\hline \multirow{2}{*}{ Properties } & \multicolumn{6}{|c|}{ The content of polysulfone, \% } \\
\hline & 0 & 5 & 10 & 20 & 30 & 40 \\
\hline $\begin{array}{l}\text { Adhesive strength, } \\
\tau, \mathrm{MPa}\end{array}$ & 24 & 24 & 25 & 26 & 22 & 17 \\
\hline Bending test, $\sigma_{\text {bend. }}, \mathrm{MPa}$ & 28 & 32 & 42 & 49 & 54 & 58 \\
\hline $\begin{array}{l}\text { Elongation at stretching, } \\
\varepsilon, \%\end{array}$ & 0.2 & 1.2 & 1.5 & 1.9 & 2.2 & 2.8 \\
\hline $\begin{array}{l}\text { Impact toughness, } \\
\mathrm{A}, \mathrm{Kj} / \mathrm{m}^{2}\end{array}$ & 4.8 & 10.4 & 19.5 & 28.2 & 37.4 & 46.2 \\
\hline
\end{tabular}

Table 2. Influence of the quantity of layers on the properties of multilayer heterogemeous polymer.

\begin{tabular}{|c|c|c|}
\hline \multirow{2}{*}{ Properties } & \multicolumn{2}{|c|}{ Polymer } \\
\hline & Polysulfone & Epoxy resin \\
\hline Quantity of layers & 2 & 1 \\
\hline Elongation at stretching, $\varepsilon$, \% & \multicolumn{2}{|c|}{2,5} \\
\hline Impact toughness $A, \mathrm{Kj} / \mathrm{m}^{2}$ & \multicolumn{2}{|c|}{32,4} \\
\hline Quantity of layers & 3 & 2 \\
\hline Elongation at stretching, $\varepsilon, \%$ & \multicolumn{2}{|c|}{1,3} \\
\hline Impact toughness $A, \mathrm{Kj} / \mathrm{m}^{2}$ & \multicolumn{2}{|c|}{24,7} \\
\hline Quantity of layers & 4 & 3 \\
\hline Elongation at stretching, $\varepsilon, \%$ & \multicolumn{2}{|c|}{1,2} \\
\hline Impact toughness $A, \mathrm{Kj} / \mathrm{m}^{2}$ & \multicolumn{2}{|c|}{25,3} \\
\hline
\end{tabular}

Structure analysis of the produced hybrid bindings was conducted by the means of scanning electronic microscope FEI Phenom with the image resolution up to 50 nanometers.

The material of the samples' surface consisted of 30 polysulfone mass fractions and 70 epoxy oligomer mass fractions produced in accordance with the first technology. The frontal surface (Figure 1(a)) was initially analyzed. Afterwards the surface of the same samples was investigated at various magnifications after the bending test was conducted (Figure 1(c)). The acquired data analysis allows to draw a conclusion that the material microstructure is not homogeneus and polymeric phases are mutually distributed chaotically (epoxy matrix is shown in white in Figure 1). Mixing mode change towards the mixing duration increase did not result in structure improvement. We assume that polymer mixture inhomogenous structure is related to the errors in mixture preparation technology, so its further improvement is required. Nevertheless, even this imperfect structure demonstrated the fundamental increase in polymer binding deformation parameters (see Table 1).

The structure of layered hybrid binding, produced by the second method with 4 polysulfone and 3 epoxy olygomer alternating layers is shown in Figures 2-4.

On Figure 2 there are visible characteristic cracks that always appear on a layer of an epoxy oligomer while bending tests being performed. On Figure 2(a) the epoxy olygomer layer destruction №1 (from the sample frontal surface) took place. On Figure 2(b) the destruction of the 3rd epoxy oligomer layer took place. The surface distraction microstructure at bending tests (Figure 3) and impact strength tests (Figure 4) is different, however in both cases epoxy material destruction took place, while polysulfone layers have kept the integrity. 


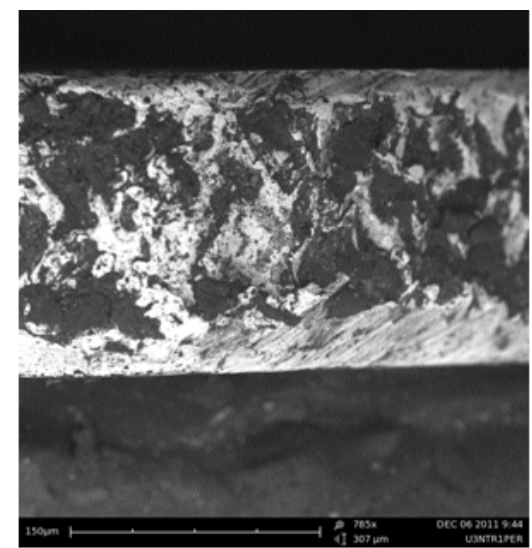

(a)

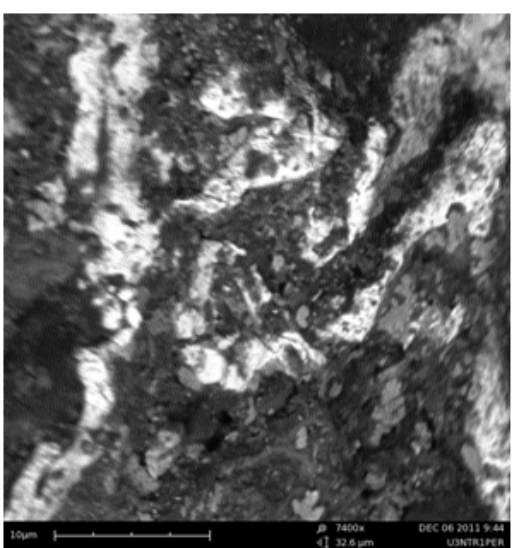

(b)

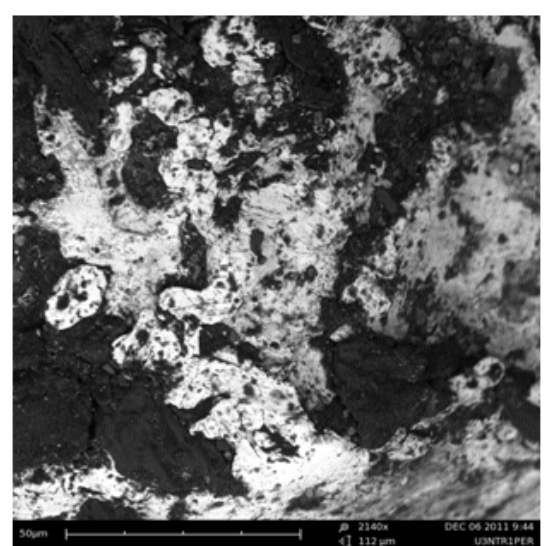

(c)

Figure 1. Fracture surfaces of epoxy matrix, content of $30 \%$ polysulfobe for different microscope approach ((a) $\times 800$, (b), (c) $\times 2060$ ).

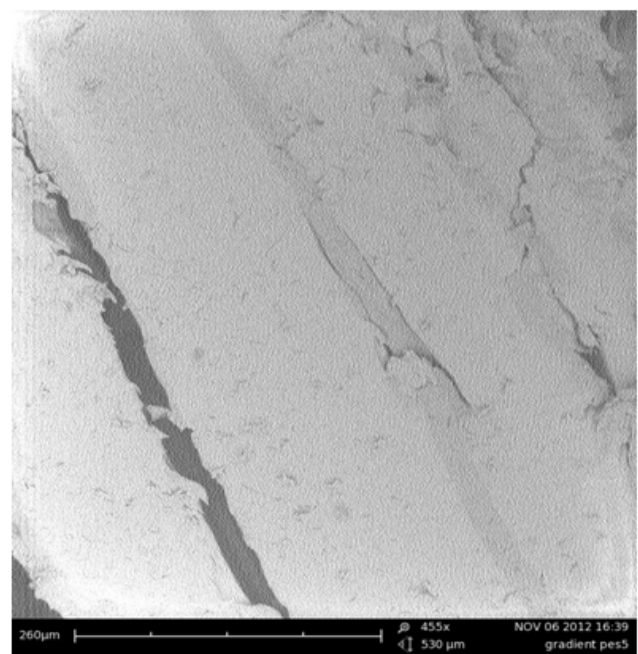

(a)

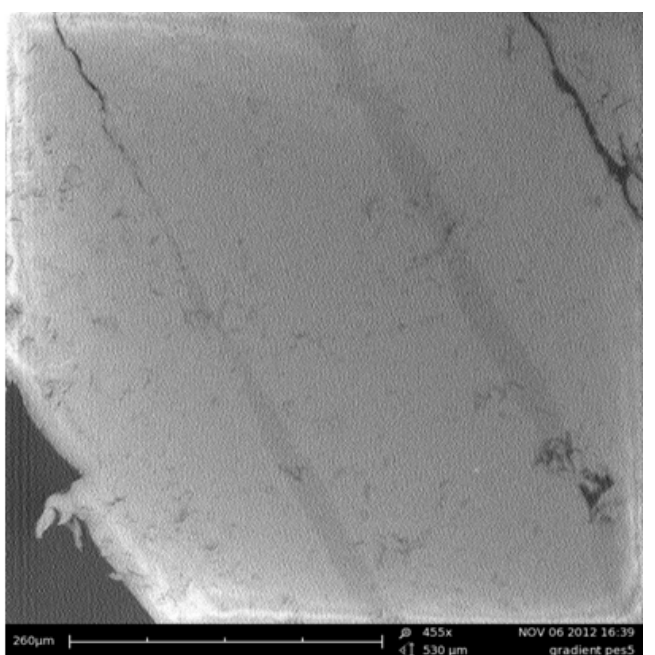

(b)

Figure 2. Multilayer polymer consist of 4 layers of polysulfone and 3 layers of epoxy resin (a) and 3 layers of polysulfone and 2 layers of epoxy resin (b).

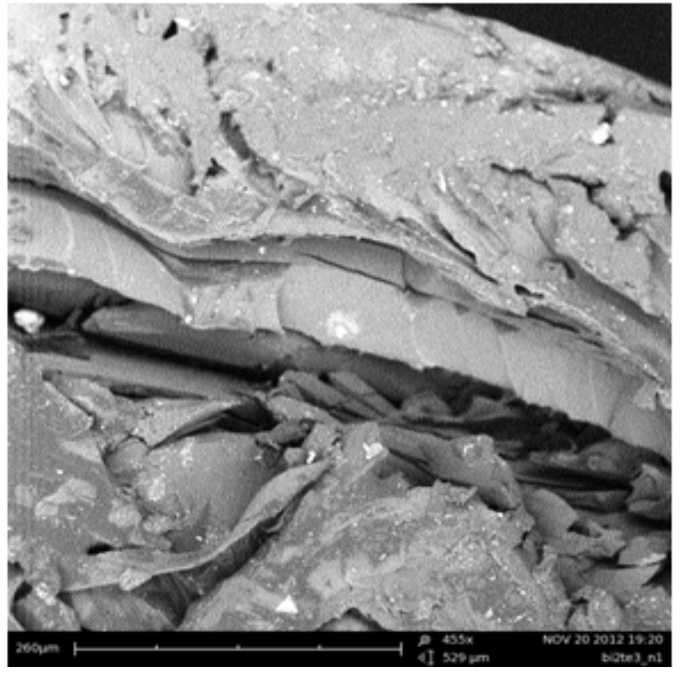

(a)

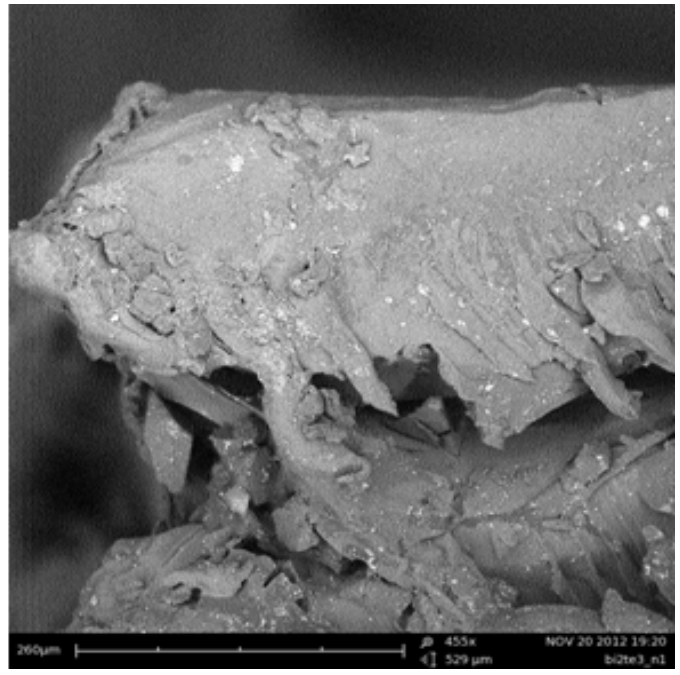

(b) 


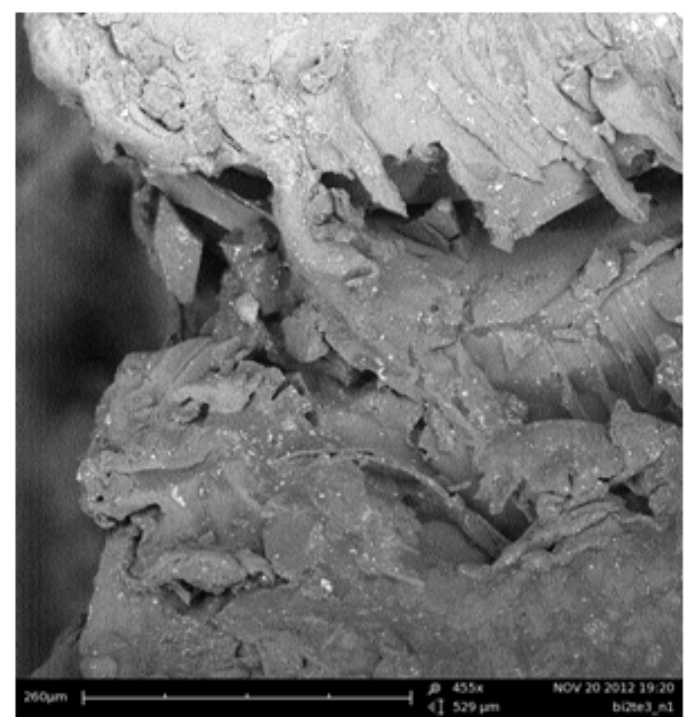

(c)

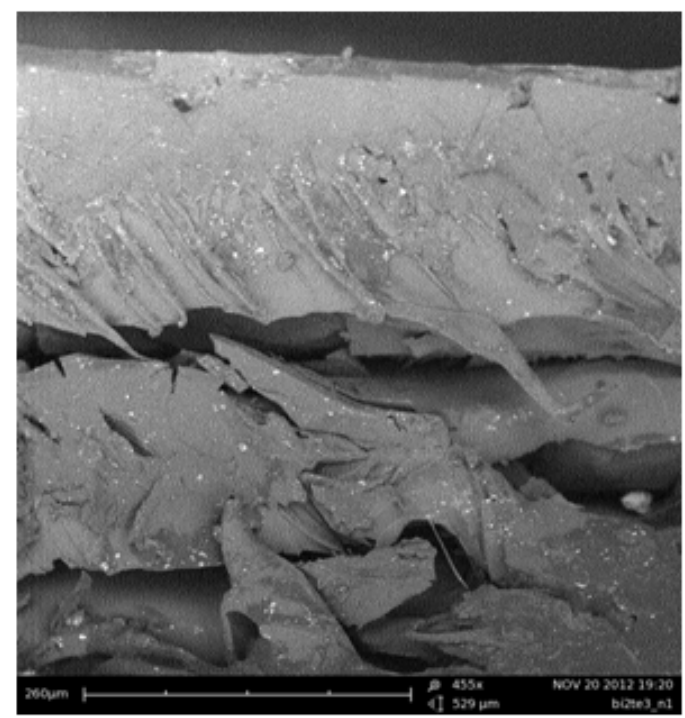

(d)

Figure 3. Fracture surfaces of multilayer polymer consist of 3 layers of polysulfone and 2 layers of epoxy resin after bent test ((a), (b), (c), (d))—different samples).

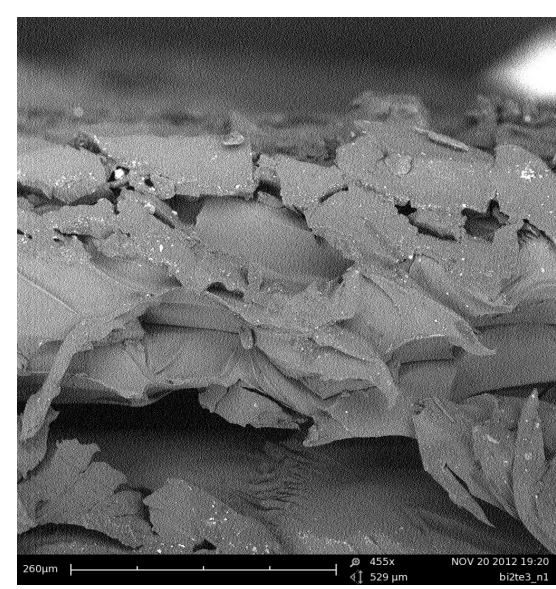

(a)

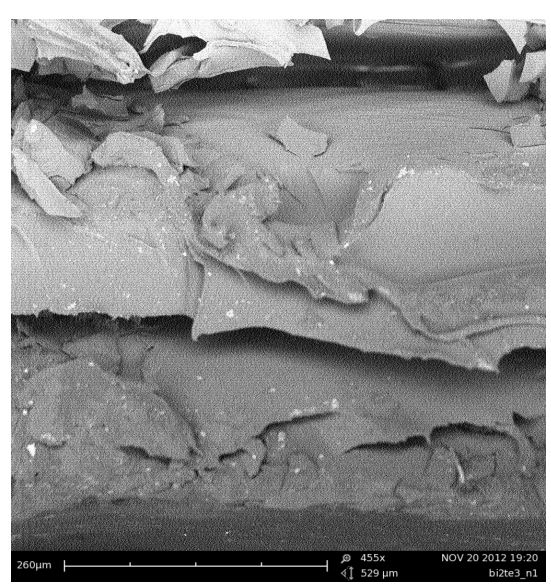

(b)

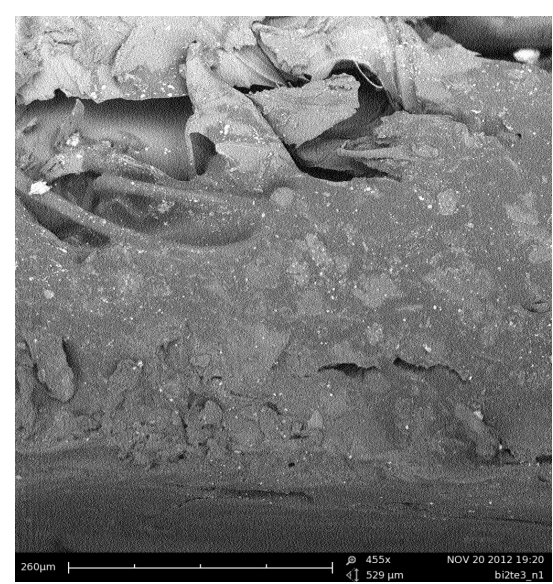

(c)

Figure 4. Fracture surfaces of multilayer polymer consist of 3 layers of polysulfone and 2 layers of epoxy resin after impact strength test ((a), (b), (c))—different samples).

After-destruction surface analysis indicates that fracture pattern depends on binding fabrication techniques. For the material manufactured via method № 1(mixing in the block), despite nonuniform polysulfone mixture in the epoxy material, interphase fracture does not happen. For the material manufactured via the second method (multilayered polymer) the layer of an epoxy material and interphase boundary between polysulfone and epoxy material layers destruct in the first place.

\section{Conclusion}

Results based upon this experiment indicate that injecting polysulfone as plasticizer in the epoxy binding significantly improves its deformation parameters. This devel- oped material can be recommended as a matrix at production of various three-layer sandwich panels for aircraft interiors, such as catering blocks, fuselage trim elements, various passenger luggage accommodation equipment of various design which experiences impact stress.

\section{Acknowledgements}

This work was supported by the Chinese international science and technology program (No. S2012HR0080L).

\section{REFERENCES}

[1] A. Muranov, G. Malysheva and A. Pilyugina, “The Po- 
lymeric Heterogeneous matrix for Composites," ACMTAA-2012, Werxham, 2012.
[2] M. Kerber and I. Gorbunova, "Binders for Polymeric Composite Materials,” Plastics, No. 12, 2010, pp. 14-21. 